\title{
El jardín romántico en la España ilustrada: Una visión en la literatura
}

\author{
Victoria Soto Caba *
}

Los jardines han sido siempre símbolos recurrentes de poetas y toda suerte de escritores. Esa predilección especial por cantar o narrar las bellezas de un jardín ha conformado, desde la Antigüedad, un "topos" literario, una imagen tópica y ambivalente. Sin embargo, la imagen del jardín en la literatura es también un signo esclarecedor de una sociedad y de una cultura determinadas. La literatura es portadora de formas innovadoras y esa imagen tópica, ese "lugar común", no fue sólo un marco escénico o una metáfora lírica, sino una consciente propuesta estética en la mayor parte de los escritores '.

Frente al innegable carácter tópico del jardín en la obra literaria, hay igualmente que aceptar su carácter premonitorio, un aspecto que puede configurar, como ha señalado Corrado Rosso, una tentativa de propuesta tipológica, ya que los jardines recreados por poetas y escritores son producto de la fantasía y de la imaginación, de jardines ideales, pero también de jardines reales, una especie de criatura mixta entre lo real y lo ideal, algo hecho a base de diversos estratos de la realidad ${ }^{2}$. De alguna forma, esta simbiosis entre realidad y fantasía favoreció e impulsó el desarrollo de nuevos modelos jardinísticos a lo largo de la historia.

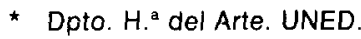

Fénomeno comparable con la pintura. Para Praz, Mario, "la poesía y la pintura han marchado siempre codo con codo, en fraternal emulación de metas y medios expresivos", Mnemosyne. El paralelismo entre la literatura y las artes visuales. Madrid, Taurus, 1979, pág. 10. Para el caso concreto del jardín y la literatura ver capítulo «Estructura telescópica, microscópica y fotoscópica», págs. 153 y ss.

2 Cfr. Rosso, C., «Per una tipología del giardino» en La letterature i giardini (Atti del Convegno Internazionale di Studi di Verona-Garda, 2-5 ottobre, 1985). Firenze, Leo S. Olschki Editore, 1987, pág. 17. 
El eco anticipador y el presagio que tuvo la literatura, en este sentido, es uno de los fenómenos más palpables a la hora de estudiar la repercusión que el jardín inglés tuvo en Europa. No es extraño que el siglo XVIII, al descubrir los aspectos más incontrolables y salvajes de la Naturaleza, más sublimes o tormentosos, optara también por ensalzar el nuevo tipo de jardín sensorial y emotivo que había surgido, durante las primeras décadas del siglo, en Inglaterra y se había extendido rápidamente por gran parte del continente europeo. Precisamente no fueron ni arquitectos ni jardineros los responsables de la revolución dieciochesca en el arte de la jardinería, sino filósofos y poetas, como Shaftesbury, Joseph Addison y Alexander Pope, entre otros, los que atacaron las formas rígidas y geométricas de los jardines clásicos y en particular las formas encorsetadas y simétricas de los modelos franceses. Con sus escritos pusieron en marcha el denominado "movimiento paisajístico", por el cual el jardín debía ser entendido como mera naturaleza, como un paisaje natural libre de parterres, de tijeras y escuadra, de cualquier disposición geométrica y perspectivica.

\section{POESIA Y JARDINES...}

Las nuevas teorías inglesas surgieron cuando las cortes de toda Europa imitaban la normativa de la jardinería francesa, a través de La theorie et la pratique du jardinage (1709), de Dezallier D'Argenville, un tratado que codificaba los trabajos empíricos de Le Nôtre y cuyas ediciones traspasaron la segunda mitad de la centuria. Los principios de la jardinería inglesa se plasmaron pronto en la tratadística europea y en la década de los años setenta el francés Watelet (Essai sur les jardins) y el alemán Hisschfeld (Theorie der Gartenkunst) demostraron la favorable aceptación de un jardín «natural», de un jardín paisajista " ambientado» con pequeñas y exóticas arquitecturas. Pero, con anterioridad a los tratados, la Encyclopédie tomó posiciones en favor del modelo inglés, con argumentaciones derivadas de poetas y filósofos, como Milton, Thomson y Addison ${ }^{3}$. También y antes de las primeras realizaciones prácticas de jardines anglochinos en Francia, las corrientes británicas de la jardinería calaron en la literatura identificándose con el ideal de «retorno a la naturaleza». Rous-

3 Sobre el tema véase en particular Calatrava Escobar, J.A., La teoría de la Arquitectura y de las Bellas Artes en la Encyclopédie de Diderot y D'Alambert. Granada, Diputación Provincial de Granada, 1992, especialmente págs. 312-320. 
seau en La Nouvelle Heloise (1761) describía un jardín que tendría su repercusión en el trazado del parque de Ermennoville.

La prueba del éxito y de la expansión del nuevo trazado en Europa y, particularmente en Francia, se encuentra sobre todo en la poesía. Una especie de polémica entre partidarios del jardín inglés o pintoresco y los defensores del estilo francés se refleja en la producción francesa desde $1760^{4}$. Poetas como Saint-Lambert, Roucher y Delille ejercieron una influencia considerable y representan una parte del conflicto que caracterizó la pugna entre el racionalismo clasicista y el incipiente sentimiento romántico hacia la naturaleza ${ }^{5}$. De todos ellos destaca el abate Jacques Delille con su largo poema Les jardins, publicado en 1782, claro exponente del cambio de gusto en Francia. Sus versos manifiestan la superación del modelo versallesco, "Cuya vista se fatiga ante los diseños uniformes" ${ }^{6}$ y al que califica de «poco alegre». Por el contrario, prefiere el nuevo estilo, "amante respetuoso de la Naturaleza" que "con arte convierte en belleza el desorden". Resumía los caracteres esenciales de naturalidad y variedad, a través de un repaso por los jardines orientales y paisajistas del panorama europeo, pero evocaba ante todo un prototipo de jardín natural o parque ajardinado que no debía caer en manierismos y ridiculeces arquitectónicas: «Acepto su uso, pero no su exceso / Arrojad de los jardines la mescolanza confusa / de construcciones diversas acordes con la moda, / obeliscos, rotondas, kioskos y pagodas" '. Con ello criticaba las exageraciones que los jardines a la inglesa tuvieron en Francia desde fechas tempranas, una crítica que procedía de los propios viajeros británicos cuando vieron las realizaciones que se llevaban a cabo en Europa, y en especial en Francia durante las últimas décadas del siglo XVIII, crítica que también reflejaba la difusión que en el continente tuvieron los tratados y ensayos ingleses. El más conocido y polémico en este sentido, fue $A$ Dissertation on Oriental Gardening (1772) de W. Chambers, una obra que no sólo determinó la propagación de lo chino, de las ruinas y de todo tipo de construcciones exóticas, sino también la aparición de catálogos y repertorios de estampas de caprichosas arquitecturas encaminadas a

\footnotetext{
4 Cfr. Giraud, Yves, "La Poésie des jardins au xvill siècle. Les goûts et les modes» en La letterature e i giardini, ob. cit., págs. 289-311.

5 Véase además CorRado Rosso, "Per una tipclogía del giardino" en La letterature e i giardini, ob. cit., págs. 20 y ss.

6 "L'oeil, qui des plans tracés para l'uniformité / Se fatigue et s'élance à leur extrémité", DeliLle, J., Les jardins ou l'art d'embeilir les paysaqes, ed. París 1852.

“Mais j'en permets l'usage, et j'en prosais l'abus / Bannissez des jardins tout cet amas confus / D'edifices divers, prodigués para la mode / Obelisque, retonde, kiosk, et pagode", lbidem, pág. 299.
} 
repoblar las distintas escenas de los jardines. El poema del abate Delille fue consultado por los diseñadores de jardines, funcionó casi como si fuera un manual o tratado y es quizá uno de los ejemplos más significativos de esta transposición artística del jardín en una obra literaria.

En el caso español no puede argumentarse una controversia o defensa semejante en favor del jardín inglés. Sin embargo, durante el último tercio del siglo XVIII, numerosos autores españoles reflejaron en sus escritos esa nueva concepción pintoresca y «natural», un reflejo que pronto se convertiría en una postura de aceptación y de partidismo hacia el nuevo modelo jardinístico.

Para entender este eco literario hay que tener en cuenta los contactos y relaciones entre España y el extranjero, el intercambio científico que facilitó a numerosos hombres de ciencias - botánicos, químicos, médicos- perfeccionar sus estudios en Francia e Inglaterra. Una política que se remonta a la primera mitad de la centuria, aunque fue a partir del reinado de Fernando $\mathrm{VI}$ cuando esta actuación de subvencionar estudios en el exterior se realizó de una forma más sistemática ${ }^{8}$. A ello hay que añadir el interés que fueron tomando los estudios de lenguas extranjeras, en especial el inglés, entre los autores españoles. Ya en 1737 el Diario de los Literatos anunciaba la «nueva Grammatica para aprender el Inglés» en su sección dedicada a los libros publicados en otros países ${ }^{9}$. Numerosos autores, como Ignacio Luzán, Juan de Iriarte o José Cadalso, conocieron la literatura europea del momento a través de sus viajes por Europa, y los que no viajaron, como el padre Feijoo, aprendieron idiomas, recibieron libros de otros países y estuvieron suscritos a las publicaciones periódicas más renombradas de la época, como el Journal de Savants. En 1776 Juan Meléndez Valdés escribía a Jovellanos que estaba "aprendiendo la lengua inglesa, y con un ahínco y un tesón indecible» ${ }^{10}$, recibiendo un año después la traducción que del primer canto del Paradise Lost de Milton había realizado el político asturiano ". Los versos impresos en Inglaterra fueron lectura asidua en los círculos ilustrados. Nigel Glendinning ha estudiado como los españoles gustaron de «un nuevo tipo de

8 Véase Balaguer Peregüell, E., "Ciencia e llustración: La incorporación de España a la Revolución Científica" en La llustración Española (Actas del Coloquio Internacional celebrado en Alicante, 1-4 de octubre, 1985). Alicante, Instituto de Estudios Juan Gil-Albert, 1986, págs. 13-33.

9 Diario de los Literatos de España, En Madrid, por MARiN, Antonio, 1737 (ed. facsímil PuvillLibros. Barcelona 1987), tomo II, pág. 380 .

10 Jovellanos, G.M., Obras Completas, Tomo II (Correspondencia: 1767-1794), ed. a cargo de J.M. Caso González. Oviedo 1985, págs. 45 y ss.

11 Ibidem, pág. 46. 
poesia pastoril en que se trataba de la vida vigorosa del campo (lejos del gusto afeminado y malsano de las ciudades) en términos que bastaban para apoyar las teorías fisiocráticas" ${ }^{12}$. Muchos de estos autores traducian directamente para mostrar «imágenes pintorescas", exóticas u orientalizantes ${ }^{13}$, y algunos no pudieron evitar la imitación de los versos de Young, como fue el caso de Cadalso.

Pero además del impacto de la poesía inglesa, no hay que olvidar el predominio de la influencia francesa e italiana en la España del siglo XVIII. El país galo fue la vía de transmisión de la cultura europea a través de traducciones y de la llegada masiva de libros impresos, a pesar de la vigilancia gubernamental $\mathrm{e}$ inquisitorial ${ }^{14}$. Tanto de Francia como de Italia llegó un tipo de poesía arcádica y bucólica de gran éxito, como los poemas de Saint-Lambert sobre las estaciones, que se ajustaban igualmente a la ideología fisiocrática y verdaderos testimonios de jardines naturales. La repercusión de esta poesía extranjera, repleta de imágenes de la vida pastoril, fue decisiva en los españoles. Muchos de ellos eligieron las anacreónticas y las silvas, composiciones de elogio hacia la naturaleza y la vida del campo.

\section{EL PAISAJISMO DE LA FANTASÍA}

Si "naturaleza" y "paisaje" fueron claves esenciales en el discurrir de la poesía española, más interés ofrece, por las descripciones e imágenes de jardines, la prosa. También en la novela y desde fechas muy tempranas hubo un interés por lo pastoril y la vida en el campo, muy en la línea de la vieja alabanza de aldea guevariana ${ }^{15}$, que transformada en una concepción política fisiocrática, acabará caracterizando el pensamiento ilustrado español. Así se entiende en una obra publicada en 1737. Su título, Morir viviendo en la aldea y vivir muriendo en la Corte, es bien significativo de la palpable división de dos mundos distantes, el rural y el urbano, con dos paisajes opuestos ${ }^{16}$. El mismo autor de esta obra, Antonio Muñoz,

\footnotetext{
12 Glendinning, Nigel, "Influencia de la Literatura Inglesa en España en el siglo xvili»; Cuadernos de la Cátedra Feijoo, (1968), núm. 20 ("La literatura española del siglo xvill y sus fuentes extranjeras"), págs. 47-93.

13 Cfr. ARCE, Joaquín, "La poesia en el siglo xV!!! en Historia de la Literatura Española (ss. XVII y XVIII). Madrid 1975, págs. 363-406.

${ }_{14}$ Sobre las influencias foráneas en la poesia española. Véase ARCE, J., La poesia del Siglo llustrado. Madrid, Ed. Alhambra, 1980, págs. 30-104.

i5 La obra de Antonio de Guevara se reeditó en Madrid en 1735 y fue resumida y vivamente alabada en el primer tomo del Diario de los Literatos de España, ob. cit. artículo X.

${ }_{16}$ La conclusión del autor de la obra, MuÑoz, Antonio, no deja dudas al respecto: "Amigo,
} 
publicaba dos años después, en 1739, otra narración novelesca en la que utilizaba la fórmula del viaje para describir aspectos sociales y críticos de las costumbres y ciudades españolas. Sus referencias a los jardines del Real Sitio de La Granja

"una Ciudad con aguas numerosas

con arte tan sublime y tal traza

que en simetría forman una Plaza»

y las alabanzas a Felipe $V$, un monarca que «buen puede estar satisfecho, de que en Europa no havrá coronado que tenga cosa que se le parezcas " ${ }^{17}$, marcan el modelo jardinístico que prevalece en la imaginación de los escritores de la época. No en vano, son unas fechas en que apenas todavía se están finalizando los trabajos de los jardines de San Ildefonso bajo la dirección de jardineros y escultores franceses. Sigue siendo el modelo francés el que impera tanto en los escenarios reales como literarios.

Ahora bien, años antes el padre Feijoo en uno de sus discursos (E) no sé qué, 1734), intentando explicar uno de los principios de la creación artística, enmarcaba su ejemplo en un escenario que bien puede remitir a los singulares jardines de la estética inglesa: "un sitio delicioso cuya amenidad costeó la naturaleza por sí sola. Nada encuentran de exquisito en sus plantas, ni en su colocación, figura o magnitud, aquella estudiada proporción que emplea el arte en los plantios hechos para la diversión de los príncipes o los pueblos. No falta en él la cristalina hermosura del agua corriente, complemento preciso de todo sitio agradable, pero que, bien lejos de observar en su curso las mensuradas direcciones, despeños y resaltes con que se hacen jugar las ondas en los reales jardines... el sitio le hechiza... sus ojos se hallan más prendados de aquel natural desaliño, que de todos los artificiosos primores, que hacen ostentosa y grata vecindad a las quintas de los magnates» ${ }^{18}$. Feijoo conocía, como otros

le dixe, tu tienes razón en todo. Dios te de muy bien viaje, que si vas contento a tu Aldea, no quedo yo menos en la Corte: tu vivirás alli gustoso; y yo aquí, pues cada uno apatece su centro, aquel es el tuyo, y este es el mío, Dios me le dexe gozar por muchos años", Morir viviendo en la Aldea y vivir muriendo en la Corte. Madrid 1737, pag. 74,

17 Muñoz, Antonio, Aventuras en verso y prosa del insigne.

18 Teatro Crítico (T. VI), en B.A.E., T. 56, (Obras del Padre Feijoo). Madrid 1952, pág. 349. Como ha visto Russell P. Sebold, Juan Pablo Forner recogió el pasaje de Feijoo para explicar el principio liberalizador de la poética, cfr. El rapto de la mente. Poética y poesía dieciochescas. Madrid, Editorial Prensa Española, 1970, págs. 113-114. «Era aquel recinto una ancha capacisima plaza, ceñida de muchos, variados y espesos árboles, grandemente frondosos; ámbito en que la naturaleza quiso manifestar la preferencia de su hermoso desaliño a la sequedad simétrica con que debilita el arte muchas veces...", en FORNER, J.P., Exequias de la Lengua Castellana. Madrid, ed. J. Pérez del Hoyo, 1972. 
muchos novatores ${ }^{19}$, los artículos de Addison publicados en The Spectator y no sería arriesgado indicar que recogió ciertas consideraciones que sobre la naturaleza y el arte aparecieron en $1712^{20}$.

El benedictino asturiano fue sumamente crítico con los escritores de su generación que continuaban las formas y las estructuras de la prosa barroca del siglo anterior, declarándose partidario de "la naturalidad y espontaneidad", una influencia de la narrativa y la lírica francesa que conseguía la "belleza de un modo natural". Como los nuevos jardines, el artificio en la obra literaria debía ser natural y espontáneo, y Feijoo consideraba sus obras "más bien como jardines en que las flores brotan espontáneamente que cuadros en que se representan con arte» ${ }^{21}$.

Pese a las recomendaciones de Feijoo y otros críticos, los tópicos expresivos del Barroco continuaron hasta mediados de la centuria. Sin embargo, y como ha señalado Alvárez Barrientos, la prosa de las primeras décadas de siglo sirvió "de expresión de los debates culturales e ideológicos» y debe entenderse "más como vehículo de ideas que como forma literaria o artística" ${ }^{22}$. En este sentido, habría que citar un texto perteneciente a una obra de Francisco Botello de Moraes publicada durante el primer tercio del siglo xvIII. Se trata de la Historia de las Cuevas de Salamanca; un obra que si bien responde al final de una trayectoria literaria propia del siglo XVII, por su discurso hermético, por su carácter de relato mitológico y por ser uno de los últimos sueños ficticios del barroco, es por otro lado considerada como una obra renovadora, por ser una de las primeras novelas utópicas y un texto de literatura fantástica que estuvo ausente en nuestro país hasta finales del siglo XVIII. Una obra, en definitiva, que debe contribuir a rescatar un aspecto de la llustración, lo que se ha denominado como «la cara oscura del Siglo de las Luces" ${ }^{23}$ y que se situa en un primer momento cultural de la renovación ilustrada ${ }^{24}$. La descripción utópica de la naturaleza que el autor nos ofrece

19 Sobre la figura puente de Feijoo, barroco e ilustrado. Véase MARAVALL, José Antonio, «EI primer siglo xvill y la obra de Feijoo» en las Actas del /l Simposio sobre el P. Feijoo y su siglo. Oviedo 1981, págs. 151-195.

20 Véase ADDISON, Joseph, Los placeres de la imaginación y otros ensayos de The Spectator ed. a cargo de Tonia Raquejo. Madrid, Visor, 1991, cap. IV, págs. 153-159.

21 Cit. por GlendinNing, Nigel, El siglo xvil, vol. IV de la Historia de la l.iteratura Española, Barcelona, Ariel, 1974, pág. 72.

22 Álvarez Barrientos, J., La novela del siglo xviII. Madrid, ed. Júcar, 1991, pág. 31.

23 Véase los artículos de CARNERO, Guillermo, recogidos en La cara oscura del Siglo de las Luces. Madrid, Cátedra-Fundación juan March, 1983.

24 Recojo las ideas y comentarios que sobre la obra ha realizado Fernando Rodriguez de la Flor en la "Introducción" a BOTELLO DE MORAS, F., Historia de las Cuevas de Salamanca, edición de Eugenio Cobo. Madrid, Tecnos, 1987. 
nos remite al locus amoenus y la bucólica renacentista, así como a los aspectos más mágicos y fantásticos del transmundo literario; sin embargo, hay un texto en particular, en el Libro VII, que, sin mencionar el término jardín, ofrece un escenario que se aproxima claramente a un jardín pintoresco o paisajista. El protagonista sueña que se encuentra en una "campaña hermosa, poblada de objetos rústicos, dispuestos más a la sólida beldad de la naturaleza, que a la desordenada fantasía de la ambición" ${ }^{25}$; molinos con humildes techos y chozas podrían aludir a ese escenario típico de pequeñas y rústicas construcciones que promovió la estética del nuevo jardín; pero lo que se aproxima más es un pequeño río que "corría por en medio del terreno... formando varios giros como en meandros", navegado por cisnes blancos y poblado de numerosas fuentecillas.

Es cierto que una descripción así responde a un tópico paisaje arcádico y que el testimonio de Botello de Moraes, por sus fechas, es un documento prematuro para valorarlo como ejemplo o reflejo de una trasposición de la estética inglesa. Sin embargo, sirve de alguna forma como preludio de esa vuelta a la naturaleza que se opera en el pensamiento europeo del siglo XVIII, aunque en el caso de esta obra sea una vuelta "quimérica" y de rasgos fantásticos y de signo bien distinto.

El viaje fantástico de Botello de Moraes ha sido visto también como una utopia, un itinerario imaginario que al ocuparse de la naturaleza, aunque sea irreal, plantea una alternativa distinta a las utopías sociales urbanas características del siglo, en particular a la posterior Sinapia. La Descripción de la Sinapia ignora el trazado del jardín que todas las casas tienen en los distintos barrios; pero, como ya observó Miguel Avilés, la estética que predomina en la obra está claramente ligada al gusto neoclasicista por sus continuas referencias a la disposición simétrica y uniforme ${ }^{26}$.

No es, por tanto, en la utopía sino en la fantasía donde hay que buscar los escenarios de los nuevos jardines. Una fantasía literaria muy ligada a las leyendas e historias de viajes que permitían ofrecer una nueva geografía y ser vehículo expresivo de una naturaleza alejada del control de la civilización urbana. Es el siglo de las grandes expediciones y los des-

25 Ibidem, pág. 238.

26 Aunque el autor de esta península ibérica transfigurada señala, al hablar de su geograi,, de la "agradable variedad" que presenta su paisaje, montes, ríos... Cfr. Sinapia. Una utopia Española del Siglo de las Luces. Madrid, Editoria Nacional, 1976, edición de Miguel Avilés, pág. 77. 
cubrimientos de la historia natural. Es el siglo del éxito de Robisón Crusoe y Los viajes de Gulliver. La obra de Swift fue traducida al español y editada en 1793. Las imitaciones de estas obras, que proliferaron en toda Europa, acabarán siendo traducidas por Justo de la Barra o Tomás de Iriarte a finales de siglo ${ }^{27}$.

Pero varias décadas antes, en 1769, Joaquín Vaca de Guzmán y Manrique traduce del italiano una obra de mayor interés por sus claras posiciones con respecto al jardín. Se trata de los Viajes de Enrique Wanton a las tierras incógnitas australes y al país de las Monas..., escrito por el conde Zaccaria Serimán y que gozó de gran popularidad desde su aparición en Italia en 1749. La obra es una sátira contra la sociedad y sus costumbres que recurre al esquema narrativo del viaje y al naufragio de varios protagonistas que acaban encontrándose en una isla, en un país fantástico: en un país de simios.

Vaca de Guzmán tradujo la obra y la continuó con nuevas aventuras durante los años sucesivos. Pero al margen que la adaptara a la situación española -en los últimos volúmenes - ${ }^{28}$, el traductor repitió lo que los escritos teóricos y tratados de jardinería europeos insistían por las mismas fechas. Los protagonistas, perdidos en la isla, llegan a una casa de campo rodeada de arroyos, frutales y sembrados, un escenario que según el autor era casi una pintura: “parecía un jardín, y los objetos, que se presentaban a nuestros ojos, formaban una de aquellas delicias, que la pintura suele con frequencia representar a nuestra vista, pero que jamás o mui raras veces nos hace gozar la naturaleza" ${ }^{29}$. Resulta inevitable plantear la relación entre los orígenes del jardín inglés y la pintura de paisaje, un aspecto fundamental en la teorización del nuevo trazado ${ }^{30}$. La imágen bucólica de la villa campestre, como una escena pictórica, se contrapone al jardín del palacio del Sr. Haya, el marco en donde continuan las aventuras de los viajeros perdidos.

${ }^{27}$ El primero se ocupó de Los Dos Robisones, mientras que Iriarte tradujo El nuevo Robinson del alemán Campe. Sin embargo, no llegó a editarse en castellano hasta 1835 y en París.

28 Asi lo considera Álvarez Barrientos, J. ob. cit., pág. 134.

29 Viajes de Enrique Wanton a las tierras incógnitas y al pais de las Monas... Traducidos del idioma inglés al italiano y de éste al Español por D. Joaquín de Guzmán y Manrique. En Alcalá... En la Imprenta de Doña Maria García Briones, Impresora de la Universidad, año de 1769, tomo 1, pág. 34.

${ }_{30}$ Los paisajes italianos de Lorraine, Rosa y Poussin fueron objeto de admiración entre los británicos por sus ruinas y naturalezas de apariencia salvaje; de ahí que autores como Richardson WRIGHT hayan considerado que el punto de partida para el movimiento paisajista fuese Italia, cfr. The Story of Gardening. New York, Dover Publications, 1934. 
Prescindiendo de la autoría y de la objetividad en la versión castellana, la novela, por su carácter satírico y crítico, es también un interesante testimonio de reflexiones artísticas. En el comentario sobre la arquitectura y los arquitectos hay una innegable oposición a la decoración barroca, ya que al aludir al referido palacio señala: "La mayor hermosura del palacio consiste en mil superfluos adornos, que sirven de perfecto gusto a los ojos del vulgo; pero que son fastidiosos a los inteligentes.... ${ }^{31}$.

Lógicamente y por tanto: «El jardín no era del mejor gusto», y el autor explica el porqué: la naturaleza se encuentra «esforzada y ceñida a aquellos efectos que son del todo contrarios a su instinto. Registrábase, por exemplo, un arbol cortado en figura de una Mona, una cifra compuesta de pequeños boxes, a los que impedían, que creciesen, para que conservasen aquella bizarra figura, y finalmente todas las cosas estaban dispuestas, y obligadas a seguir unas sendas opuestas a lo que las suele destinar la naturaleza" ${ }^{32}$. Repudiaba también el parterre y las flores "Colocadas con tal orden, y estudiada proporción, que el artificio, que en ellas afectadísimamente se echaba de ver, quitaba todo aquel gusto, que suelen experimentar los ojos, acostumbrados a mirar las cosas en su disposición natural, y que se halla, quando se fixa la vista en un prado esmaltado de flores en tiempo de primavera; espectáculo tanto más hermoso quanto tiene de menos artificio". $Y$ junto al parterre, se reniega de los recintos de agua y estanques, "antiquísima costumbre de los pueblos más dados al luxo" ${ }^{33}$. Pero junto a la crítica se encuentran las indicaciones de cómo deben ser los jardines, aludiendo claramente al estilo paisajista: «En estos se debe imitar con el arte la naturaleza, pero en tal conformidad, que conviene, que el arte quede oculto, y que parezca producción natural, lo que es en efecto de un delicado gusto" ${ }^{34}$. Habría que añadir también de esta obra el aplauso hacia la casa de campo próxima a la ciudad, donde se ejerce la jardinería y el cultivo, la salud y una vida más conforme con la naturaleza ${ }^{35}$.

En definitiva, es en esta línea narrativa donde podemos encontrar el escenario del nuevo jardín. En los relatos imaginarios de viajes, y en esa tradición del "transmundo" que plantea una "nueva imagen del mundo", pero no como forma utópica (el caso de la Sinapia), sino como algo posible de una realidad mejor. En este sentido, este tipo de narración

Viajes de Enrique Wanton, ob. cit., págs. 100-101.

Ibidem, pág. 103.

${ }^{33}$ Idem.

${ }^{34}$ Ibidem, pág. 102.

${ }^{35}$ Ibidem, tomo II, pág. 101. 
continua durante el último tercio del siglo con una denominada «novela instructiva", que supone una revisión crítica de la sociedad ilustrada española ${ }^{36}$. Se trata de las Aventuras de Juan Luis o Historia divertida que puede ser útil, escrita por Diego Ventura Rejón y Lucas ${ }^{37}$. Su estructura es muy similar y el viaje fantástico vuelve a ser un vehículo para criticar o alabar aspectos de la capital de un país, Nogalia, que presenta muchas semejanzas con la corte madrileña. Se encuentran alusiones clarísimas a sucesos reales, como la decisión de repartir las estatuas de un palacio por plazas y paseos de la ciudad, "donde todo el pueblo las viese" ${ }^{38}$, aludiendo a la decisión de Carlos III con respecto a las que coronaban el Nuevo Palacio Real. La ciudad imaginada por Rejón se encuentra rodeada de jardines $y$, aunque los autores no fueron a veces lo suficientemente descriptivos, si que propone en su crítica una preocupación por la jardinería urbana.

\section{ESTÉTICA INGLESA E IDEOLOGIA FISIOCRÁTICA}

Todas estas referencias literarias pueden resultar tópicas, pero en cualquier caso tienen un carácter precursor, pues aparecen con anterioridad a la plasmación real y concreta de un trazado paisajista o a la inglesa en los jardines españoles. Ahora bien, aún siendo fantasías de los literatos, tales referencias son producto del conocimiento del pensamiento inglés desde fechas muy tempranas. Ya se ha mencionado anteriormente la importancia de los intercambios científicos y de los estudios de las lenguas extranjeras, en especial del inglés. Aunque los controles inquisitoriales y los censores impidieron que se publicasen en España muchas obras, como las de Voltaire y Rousseau, lo cierto es que los libros impresos en Francia, Holanda e Inglaterra circularon clandestinamente y fueron motivo de discusión, al menos ante una pequeña minoría ${ }^{39}$. Si en un primer momento los textos ingleses fueron conocidos a través de traducciones francesas, pronto numerosos ilustrados accedieron directamente al pensamiento inglés. La primera influencia más destacable se encuentra en la Poética de Luzán, cuya primera edición, de 1737, citaba ya a la figura de Addison. Partiendo de la filosofía de Locke, Luzán planteó una serie de

\footnotetext{
36 Álvarez Barfientos, J., ob. cit., págs. 229 y ss.

37 Padre de Diego Antonio Rejón de Silva, autor del Diccionario de las Nobles Artes y del poema La pintura.

38 Madrid, por J. lbarra, 1781, pág. 253.

39 Glendinning, N., El siglo xviII, ob. cit., págs. 24 y ss.
} 
reglas para la poesía que derivaban de la observación de la naturaleza y que acabarían impregnando de sensualismo la poesía española del último tercio del siglo. Meléndez Valdés confesaba a Jovellanos que a Locke, y a su Ensayo sobre el entendimiento humano, "debo y deberé toda mi vida lo poco que sepa discurrir ${ }^{40}$. Este ensayo fue esencial en los orígenes estéticos del jardín inglés. La máxima de que las sensaciones son el origen de todas nuestras ideas influyó decisivamente en la obra de Joseph Addison, y buscar "sensaciones" nuevas fue uno de los objetivos del nuevo trazado jardinístico. El conocimiento directo y de primera mano con los ensayos ingleses sorprende en nuestros ilustrados. Jovellanos, que conocía bien la obra de Addison ${ }^{41}$, envió a Fray Diego González el Essay on Man de Alexander Pope, el poeta que, en palabras de Meléndez Valdés, «me ha llenado de deseos de imitarle». También este último tenía en su biblioteca obras de Shaftesbury.

Aunque la Poética de Luzán no tuvo una valoración efectiva hasta su segunda edición, en 1789 , si preconiza la influencia de las teorías inglesas que se produce a mediados del siglo xVIII. Son las publicaciones periódicas dirigidas por Francisco Nipho o José Clavijo y Fajardo las que aseguran que estaba de moda el pensamiento británico ${ }^{42}$. En la Estafeta de Londres, de 1762, se indica que "se padece en nuestra Península la perniciosa dolencia de Inglomanía, esto es, passion inconsiderada por la Inglaterra" ${ }^{43}$, una nación "Guerrera como Roma, Comerciante como Cartago y Sabia como Atenas" ${ }^{44}$. Y fueron estas publicaciones las que primero mencionaron a aquellas figuras que, como Pope, Addison o W. Temple, estaban involucradas directamente en la teorización y difusión del jardín anglo-chino o paisajista.

La estética inglesa estuvo presente desde un punto de vista exclusivamente teórico. Todas estas referencias, procedentes de la literatura, de la divulgación periodística o de comentarios y confesiones epistolares, se proyectaban en una España en la que todavía los trazados regulares imperaban en los proyectos jardinísticos. Baste recordar el plan propuesto por Ventura Rodríguez (1770) para el palacio de Buenavista ${ }^{45} 0$ los idea-

40 Jovellanos, G.M., Obras Completas, Tomo ll (Correspondencia), ob. cit., pág. 46.

4. Sobre la influencia de Addison en Jovellanos ver la "Introducción" de Tonia Raquejo en la ed. cit. de Joseph Addison.

${ }^{42}$ Sobre ello véase Tonia Raquejo en la edición citada de Joseph Addison.

43 En Madrid, por Gabriel Ramírez, 1762, pág. XXII.

${ }_{44}$ Idem, pág. XVI

45 Navascues Palacio, P., "Casas y Jardines Nobles en Madrid" en Catálogo de la Exposición Jardines Clásicos Madrileños. Madrid 1981, págs. 118-119. 
dos, a lo largo de la segunda mitad de la centuria, para el Palacio Nuevo ${ }^{46}$. Reflejan la pauta seguida por la monarquía y la aristocracia, es decir, el estilo francés.

Tan sólo un ejemplo de la década de los 60 podría aventurar el primer diseño pintoresco en nuestra península. Se trata del Jardín de Robledo, próximo a La Granja, que fue iniciado en 1765 para el príncipe de Asturias $^{47}$. Su diseño paisajista se debe en gran parte a lo abrupto del terreno preexistente, sin embargo es aún un ejemplo “inclasificable ${ }^{48}$ y que responde a los primeros experimentos rústicos y fisiocráticos de la realeza española. Desde el reinado de Fernando VI se inició un proceso de explotación sistemática de los Reales Sitios ${ }^{49}$ : cultivos de todo tipo, granjas y molinos se insertaron en las posesiones reales como ejemplo representativo del modelo de monarquía ilustrada.

Este modelo político tuvo una clara justificación. Desde Feijoo a Campomanes, desde Torres Villarroel a Olavide, nadie obvió la miseria del mundo rural. La agricultura fue la gran preocupación del siglo y en el pensamiento reformista se definió como "la base fundamental de las riquezas constantes de un Estado". Así lo escribía Nipho en el Correo General de $1763^{50}$, mucho antes de que el Informe sobre la ley Agraria de Jovellanos (1795) pusiera el broche final y frustrado a todos los intentos de modificación del suelo agrario que jalonaron la segunda mitad del siglo xvIII español.

Aunque tímidamente atacadas por algunos ilustrados ${ }^{51}$, esas explo-

46 Entre la numerosa bibliografía sobre los proyectos ideados para ajardinar el entorno del Palacio Real debe destacarse DuRÁn, M., Proyectos no realizados relativos al Palacio Real de Oriente y sus jardines. Madrid 1935; así como el citado Catálogo Jardínes Clásicos Madrileños y DE LA PLAZA, F.J., Investigaciones sobre el Palacio Real Nuevo. Valladolid 1975; además AÑON FElIU, C., "Proyectos para los jardines del Palacio Real de Madrid" en I/ Giardino come labirinto della Storia. Palermo (s.a.), págs. 171-175 y SANCHO, J.L., “Proyectos del siglo xvil para los Jardines del Palacio Real de Madrid: Esteban Boutelou y Garnier de l'Isle" en Anales del Instituto de Estudios Madrileños, XXV, (1988), págs. 403-433

${ }_{47}$ Sobre este jardín véase QUESADA, M.J., "El Jardín de Robledo: un capricho real» en El Arte en las Cortes Europeas del siglo xvıI. Comunicaciones. Madrid, Comunidad de Madrid, 1989 , págs. 615-622.

4 a También se ocupa de este jardín Moleón, Pedro, La Arquitectura de Juan de Villanueva. El proceso del proyecto. Madrid, C.O.A.M., 1988, págs. 95-96.

49 Sobre el tema véase Martín Olivares, G. y SanCHO, J.L., “Jaime Marquet y la configuración arquitectónica de Aranjuez como Sitio Real modelo de la Ilustración bajo Carlos III» en El Arte en las Cortes Europeas del siglo xvil. Comunicaciones. Madrid 1989, pág. 433 y TovaR, V., "Consideraciones al valor de lo rústico en los Reales Sitios (reinado de Carlos III)", Fragmentos (1988), n. ${ }^{\circ}$ 12-13-14, págs. 219-231.

5o En Madrid, por G. Gabriel Ramírez, año de 1763.

51 Como el caso de Cabarrús, quien calificó las explotaciones de Aranjuez de caprichoso lujo de mal gusto, cit. por Domínguez Ortiz, A., Sociedad y Estado en el siglo xvill español. Barcelona 1984, pág. 140 
taciones de la realeza fueron también el reflejo «rousseauniano» del «retorno a la naturaleza" y uno de los canales por donde se integraron ciertos elementos propios del jardín paisajista. Aunque en muchos aspectos estos cultivos regios remiten a la afición lúdica del "hameau" de Versalles, muy poco tienen de jardín anglo-chino o pintoresco y presentan ante todo «una amalgama de agricultura, recetas paisajísticas y pervivencias tradicionales" ${ }^{52}$. En muchos sentidos, esto es lo que podría definir los inicios de los trabajos en el Jardín del Príncipe en Aranjuez durante el reinado de Fernando VI. El monarca mandó cercar un paraje ajardinado sobre la agrupación de antiguas huertas y su sucesor, Carlos III, a partir de 1772, encarga al jardinero Boutelou organizar un jardín a la orilla del Tajo, siguiendo el trazado paisajista. Sin embargo, este jardín a la inglesa quedaba aprisionado en un pequeño espacio, entre la Huerta de la Primavera, alineaciones de árboles y plantíos rectilíneos según un sistema ortogonal. Aunque es cierto que se levantaron pequeñas construcciones que pueden incluirse dentro de la nueva escenografía jardinística, no será hasta la década de los 80 cuando el Jardín del Príncipe adquiera un carácter más "ortodoxo».

Y hasta entonces este carácter ortodoxo es puramente teórico. Tan sólo lo encontramos en las referencias literarias, bien se trate de la poesía, como la de Meléndez Valdés, o de los periódicos y diarios más vanguardistas de la época.

Por tanto, en la España del siglo XVIII la realidad y la plasmación de la nueva jardinería es un episodio ocasional. A parte de la empresa regia del Jardín del Príncipe (cuya configuración paisajística, no se opera hasta 1784 cuando se inicia una segunda fase ${ }^{53}$ ), destaca el gusto anglo-chino de los Osuna ${ }^{54}$, con el ejemplo excepcional de El Capricho de la Alameda, comenzado en $1787^{55}$. Se trata, evidentemente, de una excepción en el

52 SANCHO, J.L., "El Real Sitio de Aranjuez y el arte del jardín bajo el reinado de Carlos III", Reales Sitios, (1988), XXV, n. ${ }^{\circ} 98$, pág. 49.

${ }_{53}$ Véase además Guerra de LA VEGA, R., Juan de Villanueva. Arquitecto del Príncipe de Asturias. Jardines y Casas de recreo en Aranjuez, El Escorial y el Pardo. Madrid 1986.

54 Cfr. Navascues Palacio, P., "Casas-Palacio de la Familia Osuna", en Jardines Clásicos Madrileños, ob. cit., págs. 125-132.

${ }_{55}$ Los estudios de mayor relieve han sido realizados por Navascues Palacio, P., "La Alameda de Osuna: una villa suburbana”, Pro-Arte, (1975), n. ${ }^{\circ}$ 2, págs. 7-26; "El Capricho (Alameda de Osuna)» en Jardines Clásicos Madrileños, ob. cit., págs. 133 y ss., y MARTínez, África, “EI Palacio de la Alameda de Osuna: un marco artístico para un salón literarion en Lecturas de Historia del Arte, II. (1990), págs. 415-419. 
ámbito de la nobleza española; los Alba, por las mismas fechas (1780) encargaban de nuevo a un arquitecto barroco, Ventura Rodríguez, los jardines para el recién acabado Palacio de Liria, proyectos que continuaban los modelos franceses. Habrá, pues, que esperar al siglo xix y sobre todo al final de la contienda independentista para encontrar la difusión de este nuevo arte.

\section{LOS JARDINES A LA INGLESA Y LOS VIAJEROS ILUSTRADOS}

Frente a este retraso hay que insistir, no obstante, en el eco que tuvo en el pensamiento literario español el trazado inglés. Pero además de los textos foráneos, la nueva jardinería fue conocida y comentada por sucesivos viajeros. Son viajeros reales, que se alejan de esa fantasía literaria y aportan otro carácter, evidentemente más objetivo para la historia de la jardinería en España, puesto que fue - al margen de la importancia que tuvieron los textos de la tratadística- un vehículo de transmisión del jardín a la inglesa de excepcional importancia.

Ya en 1751, Luzán en sus Memorias literarias de París avisaba que la belleza de los paseos y de los jardines, tanto reales como particulares, de aquella ciudad "podrán suministrar abundante materia a un viajero, que quiera ocupar su pluma en referirlos" ${ }^{56}$. Si Luzán nos privó de sus reflexiones, en un momento en que los jardines franceses acusaban claramente la influencia inglesa, sí que encaminó a los viajeros ilustrados españoles a esta tarea. Tal y como se desprende de los diarios y crónicas de los viajes, el carácter natural y las escenas rústicas de los jardines a la moda fueron ampliamente comentados y aplaudidos.

Entre los años de 1780 y 1781 , José de Viera y Clavijo realizó por segunda vez un viaje a Francia, Alemania e Italia acompañando al Marqués de Santa Cruz. En los apuntes de su Diario ${ }^{57}$ escribió que estuvo en el jardín de BELOEIL, la famosísima casa del príncipe de Ligne señalada en los versos de Jacques Delille. El ilustre canario pasó el día en esta casa de campo con el mejor espíritu afrancesado: Después de comer -escribe- me salí a dar una vuelta filosófica por los jardines expresados, para "cuya pintura no hay ponderaciones adecuadas..." ${ }^{58}$. Evocando las

56 Madrid, por G. Ramírez, 1751, pág. 12.

57 Publicado en 1848 por la Imprenta, Litografía y Librería Isleña de Tenerife.

58 Cit. por Romeu Palazuelos, Enrique, Biografía de Viera y Clavijo a través de sus obras. Tenerife, Aula de Cultura, 1981, pág. 55. 
Ensoñaciones de un paseante solitario, de Rousseau, conoció uno de los ejemplos jardinísticos más significativos de la influencia inglesa en Europa, el parque que fue cantado por el abate Delille en su poema Les jardins, publicado un año después de la estancia de Viera y Clavijo en Francia.

El ilustrado español conoció a Delille en París, según nos refiere en las apuntaciones de su Diario, y a su regreso a España se dispuso a traducir los conocidos versos. Parece ser que esta traducción estaba finalizada en 1791 y que respondía a una petición personal de Jovellanos, muy interesado por el poema ${ }^{59}$. Aunque nunca se llevó a la imprenta, la obra traducida de Los jardines o El arte de embellecer los paisajes, pues también así la había subtitulado el abate francés, fue muy celebrada en los círculos ilustrados españoles. Sin embargo, el poema francés debió llegar y ser conocido en ciertos ambientes culturales antes de la traducción de Viera.

Con toda probabilidad fue lectura de una de las aristócratas que mayor relación tuvo con las corrientes europeas: Doña María Josefa Pimentel Téllez Girón, Duquesa de Osuna, responsable de la creación de ese jardín anglo-chino o pintoresco, El Capricho de la Alameda. La duquesa formalizó la compra de una vieja villa y sus terrenos, a las afueras de Madrid, dos años después del viaje de Viera y Clavijo, en 1783, y justo en el mismo año en que otro viajero, Antonio Ponz, acometía un itinerario por varios países extranjeros.

El Viaje fuera de España se realizó en un tiempo récord, entre agosto y noviembre de ese año de 1783, un tiempo escaso si tenemos en cuenta que atravesó Francia, cruzó a Inglaterra y visitó Holanda y Flandes. La publicación del viaje, en 1785, debió convertirse en una fuente de inspiración más para la recreación de los contados jardines a la inglesa que se realizaban en esos momentos. Apenas se había iniciado la segunda fase en el Jardín del Príncipe, que vería aumentado su perímetro y sus pequeñas construcciones. Las descripciones y las peculiaridades de los jardines de Kew o Kesington visitados por Ponz no debieron ser ignorados por los jardineros y arquitectos de Aranjuez, y mucho menos por la propia duquesa que, unos años después, contrata a dos jardineros franceses, Mulot y Provost, buenos conocedores del nuevo estilo, para que realizaran su jardín de La Alameda.

Uno de los objetivos esenciales de esta estancia en Europa y que el mismo Ponz subraya era "dar alguna idea de las bellezas naturales de los territorios y del mejor cultivo de los mismos" ${ }^{60}$. En este sentido, las

PONz, A., Viaje fuera de España. Madrid, Aguilar, 1988, t. I, pág. 15. 
reflexiones y descripciones de las campiñas, bosques, plantíos y cultivos son quizá el aspecto más auténtico y destacable de este viaje de Ponz. No sería exagerado decir que el Viaje fuera de España fue para Ponz un delicioso trayecto por un paisaje frondoso que siempre anheló para el árido suelo de gran parte de nuestras provincias.

Fue en el tema de las casas de campo, sus jardines y entornos, donde Ponz más se detuvo. Desde que entra en Francia las alabanzas se dirigen al estado de los alrededores de las grandes ciudades, como fue el caso de Burdeos, rodeada de quintas, villas con grandes extensiones de bosques, cultivos y zonas ajardinadas. Los comentarios del autor al respecto son constantemente comparativos al panorama español: Yo me holgaría mucho de que nuestros poderosos y personas de conveniencias vieran el buen empleo que hacen los ricos de esta tierra de parte de sus caudales, manteniendo para su recreación, y en temporadas para su retiro, deliciosas casa de campo...", y se preguntaba "¿Cuando llegará y se adoptará esta moda útil, honesta y en todos los tiempos digna de grandes personajes...?»; y añadía que "bien quisiera que hubiera muchos de estos deliciosos desahogos en la campiña de Madrid» ${ }^{61}$.

La ausencia de quintas y posesiones campestres de este tipo o la falta de villas suburbanas no es una reflexión exclusiva de Ponz. Durante el último tercio del siglo xVIII los viajeros extranjeros observaron una particular actitud de la nobleza española. Muchos viajeros no descubrieron en todo su recorrido "una sola residencia de campo como las que se encuentran por doquier en Inglaterra, debido a que la gran nobleza permanece siempre en la Corte...» ${ }^{62}$. Esta actitud de larga tradición histórica, que adjudicaba a la aristocracia un claro papel de comparsa, en las visitas y estancias que los reyes hacian periódicamente a sus posesiones, fue lo que determinó el desprecio de los ricos por sus haciendas rústicas y el hecho que rara vez construyesen quintas de recreo en las afueras.

Era un fenómeno que no era ignorado por círculos políticos intelectuales. De hecho, las Sociedades Económicas intentaron promover ese movimiento de retorno a la tierra y ese interés por el campo: «las grandes poblaciones necesitan de estas Casas de Campo para que sus moradores acaudalados y los grandes personages adquieran en ellas afición y conocimiento de la agricultura" ${ }^{63}$. Las Memorias publicadas mencionaban,

61 Ibidem, carta II, págs. 72-73.

62 En Robertson, lan, Los curiosos impertinentes. Viajeros ingleses por España desde la accesión de Carlos III hasta 1855. Madrid, ed. del Serbal-C.S.I.C., 1988, pág. 139.

${ }_{63}$ Memorias de la Scciedad Económica. Madrid 1780, t. I., pág. XXV. 
como ejemplo, las villas y casinos de Italia, Francia e Inglaterra: "los Señores Ingleses, y aún los Comerciantes viven tanto tiempo en sus casas de campo como en las ciudades de su ordinaria residencia, y en algún modo la magnificencia ha huido de las antiguas moradas, y se ha trasladado a las quintas" ${ }^{64}$. Tales quintas significaban "ornato y progreso", ocupar «una gran número de familias pobres». Para terminar con las «campiñas rasas" que rodeaban a la capital estas instituciones recomendaron a los nobles que emularan los casinos que por entonces se habian realizado para los infantes y príncipe en El Escorial. El propio Floridablanca alabó «la afición a promover todo género de agricultura de los señores infantes y de su augusto hermano, el principe de Asturias", señalando que "Son bien notorios los terrenos incultos, que casi de repente han convertido sus altezas en fecundas y abundantes huertas y en jardines deliciosos" ${ }^{65}$.

El ejemplo regio y las buenas intenciones de las Instituciones no tuvieron mucho efecto. La relación, pues, entre el nacimiento de la revolución jardinística y las posesiones campestres de la aristocracia inglesa difícilmente pudo tener su reflejo en la España Ilustrada. Esa actitud general de la nobleza española fue uno de los factores más importantes para entender el poco arraigo que el jardín paisajista o la inglesa tuvo en nuestra península.

Paralelamente a las Sociedades Económicas, a los políticos y viajeros, la preocupación por la actitud indiferente de la clase terrateniente hacia el campo se encuentra también en la narrativa de las últimas décadas de la centuria. Las novelas de Pedro Montengón y de Mor de Fuentes proyectan, reiteradamente, ese «menosprecio de corte», una ideología que también se encuentra en la poesía ${ }^{66}$.

Pedro de Montengón, por ejemplo, en su Eusebio (1786-88), novela cuyos escenarios comienzan en Norteamérica y acaban en España, pa-

64 lbidem.

65 «Y los demás cultivos y plantíos que los tres hermanos han hecho en los Sitios Reales, trabajando por sus propias manos, ennobleciendo el arado y el azadón y enseñando con su ejemplo a los poderosos cual debe ser el objeto, la aplicación y el aprecio del labrador y de sus trabajos" en Obras originales del Conde de Floridablanca y escritos referentes a su persona. Madrid, Biblioteca de Autores Españoles, t. 59, pág. 328.

66 Las anacreónticas de Meléndez «no constituyen otra cosa que una suerte de propaganda de modo indirecto, encaminada a despertar en los ricos el nuevo interés en la vida rural, para de este modo revitalizar el sistema agrícola del país de acuerdo con las doctrinas fisiocráticas" en Glendinning, N., El siglo xVIII, ob. cit., pág. 127. Por otro lado, hay que notar que las recomendaciones de las Sociedades Económicas, publicadas en 1780 , coinciden cronológicamente con la égloga que, para el concurso de la Academia, envió Tomás de Iriarte con el título La felicidad de la vida del campo (1780). 
sando por Inglaterra y Francia, acusa los moldes británicos al referirse a las quintas, en particular a una villa de un rico personaje en la «la arquitectura como en sus adornos había hermanado la magnificencia inglesa al gusto y primor de Italia y Francia, y al aseo de Holanda» ${ }^{67}$. La obra, prohibida en 1798 por la Inquisición, recreaba esos "verdores de los sembrados y arboledas" que había fuera de Londres, "el adelantamiento de los agricultura en Inglaterra", debido "no solo a las luces y patriotismo de algunos ministros, y a los franquezas concedidas a los labradores, sino también a los asuntos propuestos, y los premios dados a las Academias sobre ello" ${ }^{68}$. El panorama que ofrece de España causaba al protagonista compasión: "campos yermos... faltos de verdura y de frondosidad, echando de menos la industria y el cultivo que tanto le embelesaba, asi en Inglaterra como en Francia» ${ }^{69}$. No es extraño, por tanto, que las descripciones de los jardines en las novelas de finales de la centuria presenten una innegable evocación al diseño paisajista. La Leandra, una obra de Antonio Valladares de Sotomayor, publicada en 1797, es un folletín que situa sus historias de amor en diversos escenarios ajardinados donde emplea "todo su poder la naturaleza»: "Allí la naturaleza se dexaba conocer como es en sí, no como en las Cortes la presenta el luxo desordenado, el vício envejecido, la ambición, el interés, la envidia, la adulación y la iniquidad" ${ }^{70}$.

Fue Ponz con su Viaje fuera de España el autor que, al margen de teorías y tratados, debió nutrir de imágenes de este tipo a muchos literatos de finales de la centuria. Pero su gran aportación fue presentar al ilustrado español una especie de catálogo descriptivo de algunos de los ejemplos más conocidos de los jardines paisajistas de Inglaterra. Resulta muy interesante que su crónica apenas repare en los jardines renacentistas y barrocos que salpican todo el recorrido de Poitier a Orleans o París, pasando por centros como Tours o Blois; y que sean ante todo las casas de campo, sus huertas y bosquecillos lo que le llame la atención, porque en ellos «la Naturaleza unida con el arte forma uno de los objetos más agradables y pintorescos que yo he visto" ${ }^{71}$.

\footnotetext{
67 Montengón, Pedro, Eusebio, Historia sacada de las memorias que dejó el mismo..., consultada ed. de José René Massón. Paris, Casa de Masson e Hijo, 1824, Tomo II, Libro III, pág. 149.

68 Ibidem, tomo II, Libro IV, pág. 223.

6s Ibidem, tomo III, págs. 313-314.

70 Valladares de Sotomayor, A., La Leandra, Con licencia: en Madrid. Año de 1797; tomo IX, pág. 138.

${ }_{71}$ Ponz, A., ob. cit., Carta III, pág. 79.
} 
Si bien aprecia los paseos y jardines parisinos, es en Chantilly, camino de Calais para atravesar el Canal de la Mancha, donde encuentra "el sitio más delicioso del mundo". Se trata de la posesión adjunta al palacio del príncipe de Condé, objeto de los trabajos de André Le Nôtre desde 1663. Por sus estanques y fuentes, este jardín ha sido calificado como un grandioso espectáculo de arquitectura y agua, y parece ser que fue la creación preferida de Le Nôtre. A lo largo del siglo XVIII esta residencia se completó con jardines a la inglesa, cursos de ríos ondulantes y pequeños lagos salpicados de construcciones rústicas; precisamente la zona que más subrayó Ponz, a pesar de lo apurado de su visita. $Y$ es que el rasgo característico de su Viaje fue la rapidez y en más de una ocasión escribe que ciertos sitios sólo pudo verlos de paso. A lo largo del texto sorprenden frases como: "según lo que me han referido", "según me han contado", o "si pudiera detenerme más tiempo", "ya no tengo tiempo...", etc... De esta forma, cuando se dirigía a Hampton Court señala que pasó «por delante de una casa de campo, donde me dijeron que había trabajado sus obras el famoso poeta Pope..." ${ }^{72}$. Por falta de tiempo no pudo detenerse en los jardines de Stowe, sin embargo se informó lo suficiente como para recoger su extensión y las principales construcciones que decoraban este conocido parque.

Esta falta de tiempo coincide casi siempre con esas posesiones y jardines que requerian el paseo para descubrir sus peculiaridades. Pero, pese a la falta de tiempo, la opción por el nuevo trazado paisajista resulta muy clara en la obra de Ponz: "Los jardines ingleses son en extremo caprichosos y agradables, no como los parterres, cuya falta de plantas crecidas y uniformidad fastidian en cierto modo. Estos van siempre serpenteando; alternan plantas bajas con altas; ocultan... la diversidad de... figuras que sucesivamente va descubriendo quien pasea por tales jardines" ${ }^{73}$.

Resulta significativo también que el exterior de ciertos palacios, como el de Windsor o Blenheim, no sean dignos de un mínimo comentario o alabanza, y que la magnificencia resida precisamente en sus parques. Junto al diseño irregular del jardín, es sobre todo la escenografía lo que más le interesó constatar: como el puente que atravesaba uno de los canales en Belheim, imitando el de Rialto en Venecia; o el puente que sobre rocas "del acreditado arquitecto llamado Chambers" había en Wilton-House, "o el frontón que sobre una gruta ideó Iñigo Jones para el

72 Idem, pág. 224.

73 ldem, pág. 190. 
mismo jardín. De todos los jardines y posesiones que conoció en su Viaje por Inglaterra, fueron la posesión de Coban y la posesión real de Kew donde realiza una más detenida descripción, ocupándose no sólo del trazado, de las especies botánicas y su distribución, sino especialmente de las arquitecturas. De alguna forma, podría decirse que el Viaje fuera de España presentaba en su edición de 1785 un modelo pintoresco y paisajístico digno de emulación, en unos momentos en que la estética inglesa del jardín hacía su tímida aparición en el panorama español. Ponz refiere los pabellones "construidos a la gótica", los templos "de estilo griego", dedicados a Baco y otros dioses de la antigüedad, las tiendas turcas de tela estucada, y sobre todo las ruinas "fingidas del jardín». Sobre estas últimas asegura que no les falta "circunstancia" para que parezcan verdaderamente antiguas: "como las que permanecen en Roma y en otras partes de Italia, pues, al modo que en áquellas, también en éstas han crecido arbustos entre las piedras, han serpenteado hiedras en ella y nacido raíces; de modo que la Naturaleza ha concurrido admirablemente para hacer más graciosa esta invención del arte.... ${ }^{74}$. Mientras que Ponz tuvo claro ese carácter de "apariencia" y de "escenografía", la curiosa traducción que se adjudicaba Nipho del Viage de la Razón por Europa, editado también en 1783, indicaba a modo de crítica que en las casas de campo inglesas "verdaderamente encantadoras, en las que, para retratar las ruinas de Ciudades antiguas de Grecia, se habian volado edificios por medio de minas" ${ }^{75}$.

El curso del río, las grutas, puentes y la abundancia de una vegetación exótica, frondosa y cuidada, con su disposición natural eran los requisitos que ya Ponz entendió necesarios para "crear agradables y nuevos puntos de vista". Insiste en esa "fragmentación de la perspectiva" y en el carácter de sorpresa que presentaba el jardín británico: "pasando de un espacio a otro, se halla uno, sin advertirlo, con otro objeto principal, pero totalmente diverso de lo que acababa de ver ${ }^{76}$. En realidad, el ilustrado español recogía el método del jardín oriental que Chambers propuso para que se aplicara en los jardines europeos: "contribuir a una gran variedad de escenas que pueden ser contempladas desde diferentes puntos de vistam ${ }^{77}$. Estas escenas estarían caracterizadas por la incorporación de

${ }^{4}$ ldem, págs. 217-218

75 Viaje de la Razón por la Europa, por el Marqués de Caracciolo. Traducido de Francés en Castellano por Don Francisco Mariano Nipho. Con las licencias necesarias. En Madrid, por Miguel Escribano, año de 1783, pág. 106.

76 PONZ, A., ob. cit., pág. 222.

77 Chambers, W., A Dissertation on Oriental Gardening. London 1772, pág. III. Esta obra provocó que en el continente se bautizaran a los jardines ingleses de “jardines anglo-chinos». 
arquitecturas de todo tipo que excitaran la imaginación del espectador: ruinas, mausoleos, rocas, grutas, pagodas. Del jardín real de Kew, diseñado por el propio Chambers, Ponz subraya el hecho de que en estos sucesivos puntos de vista se encuentren los edificios caprichosos, como un templecillo inspirado en los antiguos de Balbek, otro arabesco, como una Alhambra, un templo chino o pagoda, una catedral gótica y una mezquita.

En muchos aspectos, puede resultar sorprendente el entusiasmo de Ponz por esta jardinería inglesa, máxime aún cuando llega a afirmar lo fastidioso de las líneas rectas y de los setos recortados, los rasgos que todavia imperaban en gran parte de los proyectos ajardinados del período carolino, y que tan alabados fueron en su Viaje de España. En sus primeros viajes por la península el aplauso se dirigía a la iniciativa real de repoblar de arbolado los caminos y paseos. Su estancia en Inglerra le hace ver que los caminos reales: "no solamente se apartan de la imaginación la fastidiosa idea de haber de caminar una línea recta de leguas, que se descubre de una vez, sino que la vista se recrea en registrar a menudo nuevos objetos" ${ }^{78}$.

Esta renuncia a la percepción completa o perspectívica del jardín tradicional aparece de forma más clara cuando Ponz, a su regreso de Inglaterra, y tras su paso por los Países Bajos, vuelve a París y se ocupa de los jardines de Versalles. La censura al jardín barroco, y en particular a los de Versalles, va a justificarla a través de la crítica del abate Laugier $y$, así, deslizar su preferencia por el jardín natural.

Las referencias que Ponz escribió sobre los jardines fueron numerosas y el Viaje fuera de España se convirtió en un texto fundamental, si no para la creación de villas campestres, sí para el posterior desarrollo de la jardinería urbana, sobre todo después de la Guerra de la Independencia. La obra debió ser gratamente consultada por muchos de sus contemporáneos.

Es posible que la propia Duquesa de Osuna, sin ignorar las lecciones paisajistas que trajeron sus jardineros franceses, encontrara en el relato de Ponz un muestrario arquitectónico perfecto para realizar su jardín. A finales de siglo este jardín ya estaba completo y se había convertido en uno de los salones literarios más concurridos de la corte. Un poeta, Ventura Aguado, escribió una loa en alabanza de este jardín ${ }^{79}$, enumerando,

7 Ponz, A., ob. cit., pág. 219.

79 Manuscrito comentado en el artículo citado de MÁRTINEZ, África. 
como años antes hicieran el abate Delille, los caprichos arquitectónicos erigidos: el templo de Baco, la abejera, la casa rústica, la de la vieja o la del ermitaño, el embarcadero... obras muchas de ellas realizadas por los hermanos Tadey, unos conocidos escenógrafos teatrales de la época.

Sin embargo, es muy curioso que el mayor especialista e historiógrafo del teatro en la España ilustrada, Leandro Fernández de Moratín, arremeta contra estas escenografías jardinísticas.

Moratín, quien ya estuvo en Francia el año de 1787 y en calidad de secretario de Cabarrús, realizó un nuevo viaje en 1792 por Inglaterra, Francia e Italia. Es evidente que el dramaturgo conocía perfectamente el Viaje fuera de España, pues no pudo evitar citarlo en las notas de su viaje y tampoco dejar de recoger esos paisajes ajardinados que tanto gustaron a Ponz. Los jardines vuelven a ser tema preferente del viajero, pero Moratín, más espontáneo quizá, disiente ya de gran parte de los caprichos arquitectónicos que por entonces disfrazaban los parques ingleses: "cosa fea y ridícula" nos dice, de "regular arquitectura" y cuyo principal defecto "es la pequeñez", refiriéndose en concreto a los jardines de Kew ${ }^{80}$. Era el "bello desorden" de la naturaleza lo que le agradaba -recogiendo sin lugar a dudas los comentarios de Ponz-. Cuando se dirige a Italia apunta en sus cuadernos de viaje la impresión que le produjo Zurich: «En estos no reina el mejor gusto: galerías, pedestales, balaustres, «pirámides, boliches de boj y murtas, donde gime la naturaleza bajo la tijera y el compás para producir formas extravagantes y mezquinas y esto en un país donde ella presenta por todas partes las más hermosas" naturalezas ${ }^{81}$. Lo mismo dirá de los jardines del palacio de Caserta:»... me parecieron muy mal: paredes de olmo, árboles pequeños todavía, calles tiradas a cordel, sin variedad, sin alegría; todo monótono, todo hecho a tijera y el compás..." ${ }^{82}$. Y lo mismo de Turín, Bóboli, etc...

La simetría para Moratín es violenta y prefiere "ver la naturaleza en el bello desorden de su libertad». Casi a manera de una máxima o sentencia, Moratín hacía la última reflexión que a propósito del jardín hicieron los literatos del siglo XVIII. El sustrato romántico de la libertad que se le otorga a la naturaleza ya se encontraba en gran parte de los ilustrados que traspasaron la centuria.

Bo Fernández de Moratín, L. Apuntaciones sueltas de Inglaterra. Barcelona, Bruguera, 1984, págs. 82-83.

81 Fernandez de Moratín, Leandro, Viaje de Italia. Barcelona, Laertes ed., 1988, pág. 30.

82 Idem, pág. 73. 
El Epistolario y los Diarios de Jovellanos son clarividentes de su sentimiento romántico hacia la naturaleza desde fechas muy tempranas. José Miguel Caso González observó como desde 1790 el asturiano "comienza a ver la naturaleza como objeto de placer sentimental» ${ }^{83}$. Pero antes, en 1787, Jovellanos en carta a su hermano confesaba su alegría por la llegada a Gijón "de árboles de Aranjuez, chopos de Lombardía y Carolina, plátanos de Luisiana y Oriente, sauces de Babilonia» ${ }^{84}$. Estos últimos, sauces llorones, que "se deben poner en sitios escogidos para aprovechar su forma graciosa y pintoresca», debían rodear toda la villa, un sueño del político que refleja, como muchos otros ilustrados, su amor hacia los árboles ${ }^{85}$. Los términos de "pintoresco," "sublime" y "bello" salpican las notas de su Diario. Son prueba igualmente de lo amplio y variado de sus lecturas, especialmente de ensayos ingleses ${ }^{86}$ que Jovellanos consiguió recibir de sus amigos británicos. Del embajador español en Londres recibe, en 1790, la obra de Edmund Burke sobre lo sublime (1757), ensayo que se editaría en 1807, Indagación filosófica sobre el origen de nuestras ideas acerca de lo bello y lo sublime, según traducción de Juan de la Dehesa. También pudo estudiar la sistematización que del concepto de «pintoresco" realizó W. Gilpin (1794) ${ }^{87}$ y vería la traducción que José Luis Munárriz realizó de los ensayos de Joseph Addison. Con ello el político ilustrado conocía a principios del siglo xIx los trabajos más destacables del pensamiento inglés, así como la estética de la nueva jardinería. Cuando en 1806, en su destierro mallorquín, Jovellanos redacta su Memoria del Castillo de Bellver, convierte la isla en un jardín paisajista ${ }^{88}$ y escribe que en sus paseos solitarios se le figuraba "ver un castillo encantado", donde se mezclan escenas bucólicas de pastores con sus ganados, sitios pintorescos y riscos con cuevas que producen horror. El tratamiento pictórico de esta descripción es digno de subrayarse, ya que son las "escenas» las que configuran el "adorno" y los contrastes de toda la natu-

в3 Caso González J.M., en la "Introducción" a Jovellanos, G.M., Diario (Antología). Barcelona, Planeta, 1992, pág. XI.

${ }_{84}$ Jovellanos, G.M., Obras Completas, tomo II, pág. 332.

as Ibidem, pág. 334.

${ }^{86}$ Sobre ello POLT, John H.R., "Jovellanos and hit English Sources. Economic, Philosophical and Political Writings", Transaction of American Philosophical Society (1964), vol. IV, págs. 573.

${ }^{87}$ Cfr. ILIE, Paul, «Picturesque Beauty in Spain and England: Aesthetic Rapports between Jovellanos and Gilpin', The Journal of Aesthetics \& Art Criticism, (1960-61), vol. XIX, n. ${ }^{\circ}$, págs. 164-174.

${ }^{88}$ Como ha observado VARELA, Javier, la descripción del paisaje y de la arquitectura palmesanas, de todo el espacio que contemplaba desde la ventana de su prisión, es una naturaleza que "se despliega a la manera de un gran jardín inglés", en Jovellanos. Madrid, Alianza Ed., 1989, pág. 197. 
raleza: «Detenerme a describir tantos objetos... [...] se ven tan graciosamente situado cada uno, y formando un conjunto $\tan$ vario y $\tan$ bien poblado, plantado y cultivado, que por más que se observa, jamás la vista apura sus gracias ni se cansa de verlas" ${ }^{89}$.

En los escritores de comienzos del siglo xix están presentes todas las tendencias subjetivas, de estados de ánimo y de actitudes propias de la nueva centuria, corriente que se ve reflejada en las novelas de los últimos años del siglo XVIII con la aparición de una manifiesta influencia de la novela gótica. En La Leandra de Valladares la naturaleza también se convierte en un escenario tormentoso de «horribles conflictos", "asombrosas desgracias" y "obscenos deseos». Aunque el 27 de Mayo de 1799 se prohibió publicar novelas ${ }^{90}$, y con ello acabar con el canal de entrada de las nuevas ideas, esta represión llegó tarde para aplacar el conocimiento del pensamiento inglés. Pero la metamorfosis del jardín y las ensoñaciones rousseaunianas se quebraron. Ninguna realización concreta se produjo durante los primeros años del siglo xix. Sólo después de la Guerra de la Independencia se activarian los proyectos urbanísticos y los nuevos jardines. ${ }^{91}$ Los destrozos que causó el conflicto bélico en algunas posesiones sería el factor determinante para incorporar el diseño paisajista, un diseño procedente más que nunca de los moldes franceses. Los modelos del vecino pais se plasmarían ahora en otras publicaciones, en otras novelas y en otros viajes. De alguna forma, serían otra visión en la literatura.

\footnotetext{
89 Jovellanos, G.M., "Descripción del Castillo de Bellver" en Obras Históricas. México, 1984, ed. de Elviro Martínez, pág. 116.

90 Álvarez Barrientos, J., ob. cit., págs. 214 y ss.

91 Un excelente estudio sobre los jardines madrileños es el trabajo inédito de LUENGO, Mónica, Imagen y estética del Jardín en la Tratadística. Jardines de Madrid. Memoria de Licenciatura, 1986.
} 
